\title{
The Oprăneşti landslide (Mehedinţi county) - evaluation, impact, solutions
}

\author{
Sandu Boengiu, Oana Mititelu-Ionuş, Claudia Albă \\ Geography Department \\ University of Craiova \\ Craiova, Romania
}

\author{
Daniel Simulescu \\ Institute of Geography \\ Romanian Academy \\ Bucharest, Romania
}

\begin{abstract}
On May 24, 2016, in Husnicioara commune (Mehedinţi county) the county road 607A (Cerneţi-Prunişor), communal road 17A (which connects to Oprăneşti village) and the electricity transport network were affected by landslides. Because of the landslide and the associated processes there were damaged both roads, embankments and all other previously built elements for the slope's stabilization, taking off the water from rainfall, combat and mitigate erosion (cassettes, supporting walls, concrete ditches, tailboards etc.). The damage to the road network consisted in the destruction of some sectors from county road 607A on a length of $443 \mathrm{~m}$ and communal road 17A on a length of $131 \mathrm{~m}$. The terrain reconfiguration which occurred because of the horizontal and vertical movements, locally destroyed the electricity transport network by collapse the supporting pillars of electric cables. Field measurements carried out from 2 to 16 June 2016 with GPS South S-82T were processed using GIS techniques and obtaining the numerical model of the landslide. After corroborating field analysis with the thematic maps resulted from the overlapping of the layers specific to the relief, lithology, land use/cover, it was established that the whole sectors affected by the landslide (DJ 607A and DC 17A) were destroyed, and that is impossible to restore them on the current emplacement. Taking into account the physical, geographical and territorial distribution of human settlements, for the reopening of DJ 607A there were identified and proposed as solutions two different routes with low risk and vulnerability to landslides.
\end{abstract}

Keywords - landslide; road network; GIS; vulnerability; Oprăneşti village

\section{INTRODUCTION}

Much of the world's road and railway network is built on embankments or in cuttings, thus, being susceptible to disruptions caused by landslides. The blockage of one or more roads by landslides can cause extensive detours and the delay of rescue and recovery operations, in those regions [1].

Although the modern civil engineering capabilities can rapidly repair the damages produced by landslides, the economic consequences of severing a major transport artery for even a short period can far outweigh the remedial costs [2].
The accurate evaluation of topographic attributes acquired with geo-referencing is an important element for the delineation and characterization of landslides [3, 4]. Positioning based on GPS satellites allows a faster localization of the attributes required for geomorphologic studies, unpublished $[5,6]$. Also, field surveys are focused to estimate qualitatively damages along these roads [7]

\section{STUDY AREA}

In Husnicioara commune, the county road 607A (Cerneţi - Prunişor), the communal road 17A (which connects to Oprăneşti village) and the electricity network were affected by mass movements in the spring of 2016. The county road 607A was affected by a landslide and other associated processes, on a length of $443 \mathrm{~m}$ (Fig. 1).

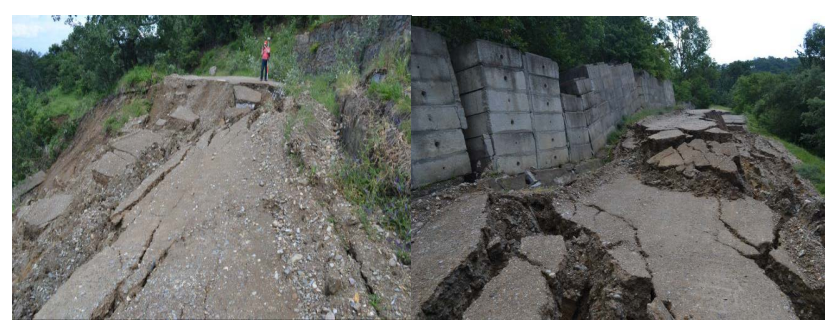

Fig. 1. DJ 607A: 1-3 m vertical displacement (left); random deformation of the road, embankments and rockfill supporting cassettes, displacement in the plane of $150 \mathrm{~m}$ (right) (Photo by Boengiu S., 16.06.2016)

The associated processes to the landslide are areas of compaction with high amplitude, collapse of large masses of material, the tilting of the packages of lithological layers left undisturbed or strongly disturbed as against their sequence and original position, the appearance of fissures and cracks with variable depths and openings, the destruction of the vegetation layer.

The communal road 17A was affected by the same landslide of a length of $131 \mathrm{~m}$, bearing the same types of processes.

The electricity network, which crossed the slided mass, was affected by the topographical reconfiguration occurred due to the horizontal and vertical movements. These led to the collapse of the pillars which supported the electric cables. 


\section{DATA AND METHODS}

Field measurements were made between 2 and 17 June 2016 using GPS South S82-T. Measurements carried out on 02.06.2016 were repeated on 16.06.2016, ascertaining the changes both horizontally and vertically. After completing the field stage it was passed to transfer the points measured with GPS in ArcCatalog.

Corrections of the field measurements were made using orthophotos, scale 1:5,000, and topographic map, scale 1:25.000, and then transposed the vector basis tot raster using 3D Analist toolbox (Features to Raster and Raster to TIN).

On the basis of a $5 \times 5 \mathrm{~m}$ network grid the numeric model of the landslide was made [8], which was then visualized in 3D using ArcScene (Fig. 2).

The digital numeric model was made using field measurements (297 points).

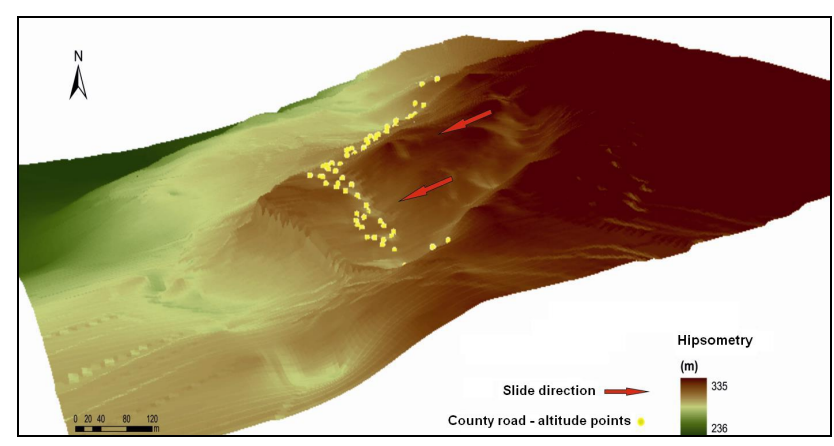

Fig. 2. The numeric model of the study area emphasizing DJ 607A (measurements and processing - June 2016).

In order to obtain the slope and slope orientation maps it was used the Spatial Analyst toolbox (Contour, Slope and Aspect) from ArcMap, with its help being achieved the landslide susceptibility map [9].

\section{RESULTS}

Changes caught between the two stages of measurements (02 and 16 June 2016), present an evolving situation. In the first stage there was a detachment with predominance of vertical movements which led to subsidence and tilting of the prism but not disturbing the lithological suite, and subsequently the movement became rotational, leading to differences in the prism's mass, its cracking and breaking in different directions, mostly to the neighboring torrential body.

For deciphering the mechanisms that contributed to occurrence of landslides and their associated processes, there were analyzed the geological (structure, lithology), geographical (relief, climate, hydrography, vegetation and soils) and anthropic components (underground exploitation of lignite) [10].

Obtaining the specific relief maps using the GPS measured point in the field confirm the vulnerability of the area (the area between Oprănești - Marmanu - Dudovița Veche - Valea Copcii localities) to landslides.

Thus, according to the hypsometry map, altitudes decrease from east to west, registering a maximum altitude of $375 \mathrm{~m}$ and a minimum of $157 \mathrm{~m}$, resulting a maximum amplitude of $218 \mathrm{~m}$; the slope map outlines geodeclivity values between 0 and 1.27, areas with higher geodeclivities are distributed mainly in the west and north, and in the east the common values are close to 0 .

The susceptibility map to landslides was drawn by overlapping slope map, slope orientation map, soils map and land use/cover map.

The landslide susceptibility values were classified on a scale from 0 (which represents a low susceptibility to landslides), to 9 (which is a high susceptibility to landslides).

A triggering component of these landslides is the undermining of the slope in the southern part by some torrential bodies that have deepened their thalweg and regressively advanced due to higher amounts of precipitation and friability of the deposits. This fact is suggested by the higher amount of material mobilized in this area, the direction of the glided materials being different from the orientation of the slope.

In conclusion, from the field observations and analysis of lithology sequence, the sand and gravels layers with thickness over $100 \mathrm{~m}$ allowed the easy infiltration of waters coming from rain and the successive moistening of clay layers at depths of approximately $40 \mathrm{~m}$. This moistening was made due to the permeability of the sands found above the clays and the above average rainfall recorded in the autumn of 2015 and in January (snow) and March-April 2016.

\section{CONCLUSIONS}

Following the complex analysis performed, taking into account the morphology of the landslide from the spring of 2016 and knowing the general behavior of gravitational processes and local conditions, we can issue the following conclusions of the road sector affected by the landslide and even anticipate further development:

- the terrain surface was strongly modified, the vertical amplitudes recording over $24 \mathrm{~m}$ while the horizontal ones 4-6 m ;

- the morphology and functionality of the slope has been changed, increasing the vulnerability to mass movements ;

- the road sectors that belong to DJ 607A and DC 17A are completely destroyed ;

- restoring the roads on the current location is no longer possible, given the risks to gravitational and old hydric processes that were greatly accentuated by recent events ;

- the temporary road towards Oprăneşti village is in the area with high landslide susceptibility and will face the same processes which led to the destruction of DJ 607A and DC 17A;

- this landslide will continue to evolve and expand until the slope will mitigate and the thresholds specific to the local lithology will not be exceeded.

As a solution to ensure and establish the connection between localities, the mitigation and stopping the gravitational processes, it was identified and proposed a new route to reopen DJ 607A which, even it is longer, it presents low risks and vulnerabilities: Oprănești Marmanu - Dedovița Veche - Valea Copcii. Another 
advantage of the new route is that it facilitates access of Marmanu and Dedoviţa Veche localities to a modernized road.

The sectors with higher slope of this road are already functional as communal paved roads, and the new part of the road which must be built crosses a quasi-horizontal plateau, without natural or anthrophic obstacles.

\section{REFERENCES}

[1] F.E. Taylor, B.D. Malamud, M. Santangelo, I. Marchesini, and F. Guzzetti, "Statistical Patterns of Triggered Landslide Events and their Application to Road Networks", in EGU General Assembly Conference Abstracts, vol. 17, p. 9992, April 2015.

[2] D.M. Lloyd, M.G. Anderson, A.N. Hussein, A. Jamaludin, and P.L. Wilkinson, P. L., "Preventing landslides on roads and railways: a new risk-based approach", in Proceedings of the Institution of Civil Engineers-Civil Engineering, Thomas Telford Ltd, vol. 144, no. 3, pp. 129-134, August 2001.

[3] C.M. Feo, L.M. Martinez, and N.C. Munoz, Accuracy and Spatial Variability in GPS Surveying for Landslide Mapping on Road Inventories at a Semi-Detailed Scale: the Case in Colombia, 2016.

[4] M. Popescu, R.D. Serban, P. Urdea, and A. Onaca, "Conventional geophysical surveys for landslide investigations: two case studies from Romania”, Carpathian Journal of Earth and Environmental Sciences, vol. 11, no. 1, pp. 281-292, 2016.
[5] S. Boengiu, D. Simulescu, and O. Ionuș, "The evolution of Breasta landslide (The Getic Piedmont, Romania). The GPS monitoring of landslide and induced risks”, The 15th Joint Geomorphological Meeting (JGM) „Fluvial and coastal systems in tectonic active areas”, 1-4 June 2011, Athens, Greece (unpublished).

[6] F. Fiorucci, M. Cardinali, R. Carl, M. Rossi, A.C. Mondini, L. Santurri, and F. Guzzetti, "Seasonal landslide mapping and estimation of landslide mobilization rates using aerial and satellite images”, Geomorphology, vol. 129, no. 1-2, pp. 59-70, 2016.

[7] P. Salvati, M. Donnini, F. Guzzetti, F. Ardizzone, M. Cardinali, F. Bucci, F. Fiorucci, M. Alvioli, and M. Santangelo, "Impact of landslides along road network and direct cost estimation: A case study in Marche Region, Central Italy", in AGU Fall Meeting Abstracts, vol. 1, p. 08, December 2014.

[8] I. Armaş, F. Vartolomei, F. Stroia, and L. Braşoveanu, "Landslide susceptibility deterministic approach using geographic information systems: application to Breaza town, Romania”, Natural Hazards, vol. 70, no. 2, pp. 995-1017, 2014.

[9] O. Ionuş, M. Licurici, S. Boengiu, D. Simulescu, and E. Marinescu, "Landslide-susceptibility analysis, mapping and validation in the Bălăcița Piedmont (South-West Romania)", The 32nd International Geographical Congress, 26-30 August 2012, Cologne Germany (unpublished).

[10] S. Boengiu, O. Ionuş, and E. Marinescu, "Man-made changes of the relief due to the mining activities within Husnicioara open pit (Mehedinţi County, Romania)", Procedia Environmental Sciences, vol. 32, pp. 256 - 263, 2016. 